\title{
Annotation of organic CoFactor molecules in PDB
}

Abhik Mukhopadhyay $^{1}$, Neera Borkakoti ${ }^{2}$, Jonathon Tyzack $^{1}$, Sameer Velankar ${ }^{1}$, Janet M. Thornton ${ }^{2}$

${ }^{1}$ Protein Data Bank In Europe, Hinxton, United Kingdom, ${ }^{2}$ EMBL-EBI, Hinxton, United Kingdom E-mail: abhik@ebi.ac.uk

A cofactor (inorganic ions and organic coenzyme cofactors) is a non-protein chemical compound or metallic ion that assists enzymes during the catalysis of reactions. Protein Data Bank (PDB) has a large number of enzyme crystal structures containing organic coenzyme cofactors. It is important to identify these organic coenzyme cofactors, when present in the 3D structure of an enzyme, in order to understand the function of the enzyme. This work will describe a workflow that Protein Data Bank in Europe (PDBe)[1], a WWPDB partner, is developing in collaboration with Prof. Janet Thornton's team to identify and annotate organic coenzyme cofactors present in PDB by incorporating information from the CoFactor database (CoFactor - The organic enzyme cofactor database)[2].

1. PDBe: improved accessibility of macromolecular structure data from PDB and EMDB.

Velankar S, van Ginkel G, Alhroub Y, Battle GM, Berrisford JM, Conroy MJ, Dana JM, Gore SP, Gutmanas A, Haslam P, Hendrickx PM, Lagerstedt I, Mir S, Fernandez Montecelo MA, Mukhopadhyay A, Oldfield TJ, Patwardhan A, Sanz-García E, Sen S, Slowley RA, Wainwright ME, Deshpande MS, Iudin A, Sahni G, Salavert Torres J, Hirshberg M, Mak L, Nadzirin N, Armstrong DR, Clark AR, Smart OS, Korir PK, Kleywegt GJ.

Nucleic Acids Res. 2016,44, D385-95.

2. The CoFactor database: Organic cofactors in enzyme catalysis.

Fischer, JD, Holliday, GL, Thornton, JM

Bioinformatics. 2010, 26(19), 2496-2497

Keywords: Cofactor, Coenzyme, enzyme 